Tropical Journal of Pharmaceutical Research April 2020; 19 (4): 893-898

ISSN: $1596-5996$ (print); 1596-9827 (electronic)

(C) Pharmacotherapy Group, Faculty of Pharmacy, University of Benin, Benin City, 300001 Nigeria.

Original Research Article

http://dx.doi.org/10.4314/tjpr.v19i4.31

\title{
Rivaroxaban versus warfarin in Chinese elder diabetic patients with non-valvular atrial fibrillation: A retrospective study on the effectiveness and associated risks (EAR) analysis
}

\author{
Shangcai Wang*, Rui Qiang, Heng Zhang \\ Department of General Medicine, Huilongguan Community Health Service Center, Beijing, 100096, China
}

*For correspondence: Email: wangshangcai@126.com; Tel/Fax: +86 1082951320

Sent for review: 17 September 2019

Revised accepted: 27 January 2020

\begin{abstract}
Purpose: To evaluate the effectiveness and associated risks of rivaroxaban against warfarin in Chinese elderly diabetic patients with non-valvular atrial fibrillation.

Methods: Data regarding demographical characteristics, clinical conditions, ischemic stroke, intracranial bleeding, gastrointestinal tract bleeding, myocardial infractions, hip/pelvic fracture, asthma, breast/prostate cancer, and death during 3-years of treatment of 584 Chinese diabetic patients with confirmed non-valvular atrial fibrillation who were placed on rivaroxaban (RX Cohort, $n=201)$ or warfarin (WF Cohort, $n=383$ ) were collected from hospital records and analyzed. Multivariate analysis was performed for the prediction of the incidence of the treatment-emergent event(s).

Results: During the 3-year treatment period, higher numbers of patients were reported for intracranial bleeding ( $p=0.042)$, ischemic stroke $(p=0.042)$, gastrointestinal bleeding $(p=0.0006)$, hip/pelvic fracture $(p=0.042)$, and asthma $(p=0.0007)$ in WF cohort than $R X$ cohort. Also, higher mortality was reported in WF cohort than for $R X$ cohort (24 vs. $4, p=0.024)$. Female sex $(p=0.031)$, age $(p=0.035)$, and comorbidities $(p=0.021)$ were associated with incidence of treatment-emergent event(s).

Conclusion: With rivaroxaban, a significant and safe risk-reduction of thromboembolic events are found in elderly diabetic patients with non-valvular atrial fibrillation.
\end{abstract}

Keywords: Anticoagulant, Diabetes, Non-valvular atrial fibrillation, Rivaroxaban, Warfarin

\begin{abstract}
This is an Open Access article that uses a fund-ing model which does not charge readers or their institutions for access and distributed under the terms of the Creative Commons Attribution License (http://creativecommons.org/licenses/by/4.0) and the Budapest Open Access Initiative (http://www.budapestopenaccessinitiative.org/read), which permit unrestricted use, distribution, and reproduction in any medium, provided the original work is properly credited.

Tropical Journal of Pharmaceutical Research is indexed by Science Citation Index (SciSearch), Scopus, International Pharmaceutical Abstract, Chemical Abstracts, Embase, Index Copernicus, EBSCO, African Index Medicus, JournalSeek, Journal Citation Reports/Science Edition, Directory of Open Access Journals (DOAJ), African Journal Online, Bioline International, Open-J-Gate and Pharmacy Abstracts
\end{abstract}

\section{INTRODUCTION}

Diabetes is a common morbidity associated with non-valvular atrial fibrillation [1] and has risk for combined endpoint events and mortality [2]. Diabetes has a greater risk of embolic events [3]. Unlike Caucasians, the prevalence of stroke in Chinese patients is associated with non-valvular atrial fibrillation and diabetes [4]. Approximately 8 million Chinese people are affected with nonvalvular atrial fibrillation [2]. The current ACC/AHA/HRS (The American College of Cardiology/the American Heart Association/the Heart Rhythm Society) Guideline for the management of patients with non-valvular atrial fibrillation recommends the use of anticoagulants 
[5] but the use of anticoagulants is less than 10 $\%$ in a Chinese population with a history of diabetes. Most of the patients received aspirin or nothing to prevent thromboembolism [6]. There is a big gap between the recommended guidelines and practice in China because antiplatelet is also frequently used instead of anticoagulant agents [4].

Warfarin is Vitamin $\mathrm{K}$ anticoagulant [7] and have been used for many years but warfarin treatment is contraindicated in elderly patients due to the risk of bleeding [4]. Also, United States Food and Drug Administration (FDA) in 2010 as an anticoagulant but has a high risk of intracranial and gastrointestinal tract bleeding [8]. Rivaroxaban is a factor $\mathrm{Xa}$ inhibitor and approved by FDA in 2011 as an anti-coagulant [9]. A once daily dose of $20 \mathrm{mg}$ rivaroxaban is the recommended dose, $15 \mathrm{mg}$ daily dose of rivaroxaban is recommended in patients with impaired kidney function, while a $10 \mathrm{mg}$ daily dose of rivaroxaban is preferred in deep venous thrombosis. The primary objective of this retrospective analysis of prospectively collected data was to evaluate the effectiveness of rivaroxaban against warfarin in Chinese elderly diabetic patients with non-valvular atrial fibrillation. The secondary endpoint of the analysis was to evaluate the associated risks responsible for the treatment-emergent event(s).

\section{METHODS}

\section{Ethics approval and consent to participate}

The protocol of the established study was approved by the Huilongguan Community Health Service Center Human Ethics Committee (no. $\mathrm{HCH} / \mathrm{CL} / 15 / 19$ dated 18 July 2019). The reporting of the analysis adheres to the law of China, the strengthening the reporting of observational studies in epidemiology (STROBE) cohort study: statement, and the 2008 Helsinki Declaration. The informed consent form was signed by all the enrolled patients or their relatives (legally authorized person) for interventions, pathology, and publication of workup in all formats irrespective of time and language during hospitalization.

\section{Inclusion criteria}

Diabetic patients within the age of $\geq 60$ years who had developed non-valvular atrial fibrillation (the arrhythmia duration $>7$ days, confirmed by echocardiography [4]) and those the physician decided to put on any anticoagulant therapy were considered for the analysis.

\section{Exclusion criteria}

Non-diabetic patients, patients who had not developed non-valvular atrial fibrillation, and patients who had been on only antiplatelet therapies (e.g. aspirin, digoxin, and/or clopidogrel) were not considered for the analysis. Patients placed on any anticoagulants therapies but who had reduced kidney function were not considered for the analysis.

\section{Interventions}

Patients who received $20 \mathrm{mg}$ rivaroxaban once in a day were considered for the RX Cohort and those who received $5 \mathrm{mg}$ warfarin per day in two divided doses were included in the WF Cohort.

\section{Outcome measures}

Data regarding the event(s) of ischemic stroke, myocardial infractions, intracranial bleeding, gastrointestinal tract bleeding, breast/prostate cancer, hip/pelvic fracture, and asthma were collected from the institutional records. If patients had occlusion of cerebral arteries in imaging diagnosis (angiography and/or the Computed Tomography), it was considered as ischemic stroke. If patients had a subarachnoid hemorrhage in imaging diagnosis (angiography and/or the Computed Tomography), it was considered as intracranial bleeding. Clinical confirmation of gastrointestinal tract bleeding was carried out as per the published algorithm [10]. Myocardial infractions and breast/prostate cancer were evaluated by imaging diagnosis (angiography and/or the Computed Tomography) or biopsies wherever applicable. Hip/pelvic fracture was validated by the x-ray image. Asthma was defined by spirometry test of lung functions [11].

\section{Statistical analysis}

InStat window version 3.0, GraphPad, San Diego, CA, USA was used for statistical analysis. The Fisher's exact test was used for categorical variable and Mann-Whitney $U$-test was used for continuous variables. Multivariate analysis was performed for the prediction of the incidence of the treatment-emergent event(s). Data were considered significant at $95 \%$ of confidence level.

\section{RESULTS}

\section{Enrollment}

From the $1^{\text {st }}$ of June 2015 to $15^{\text {th }}$ of June 2016 , there were 920 diabetic patients recorded or 
consulted in the outpatient center of the Huilongguan Community Health Service Center, Beijing, China and the referring hospitals. Among them, 85 patients had not developed nonvalvular atrial fibrillation, therefore, they were not placed on anticoagulant or antiplatelet therapies. Also, 110 patients were below the age of 60 years. So, they were not considered for the analysis.

Among the remaining patients, 115 patients were placed on only antiplatelet therapies, so these were also excluded from the study and 26 patients who received anticoagulant therapy had reduced kidney functions. Therefore, they were not considered for the analysis. Data regarding outcome measures of 584 patients who were placed on rivaroxaban ( $R X$ Cohort, $n=201$ ) or warfarin (WF Cohort, $n=383$ ) were included in the analysis (Figure 1).

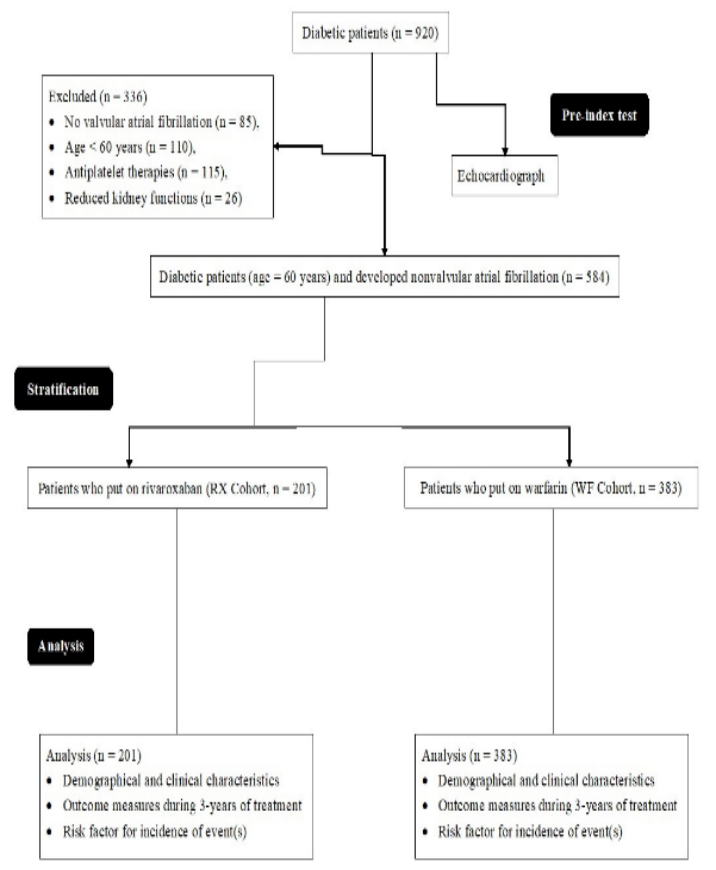

Figure 1: Flow chart of the analysis

\section{Demographic characteristics}

All the enrolled patients were new users of rivaroxaban or warfarin and no history of ischemic stroke, myocardial infractions, intracranial bleeding, gastrointestinal tract bleeding, breast/prostate cancer, and/ or hip/pelvic fracture. There was no significant difference between clinical and demographical characteristics for both groups at the start of anticoagulant therapy ( $p<0.05$ for all, Table 1$)$.

\section{Outcome measures}

During 3-years of treatment, higher numbers of patients were reported for intracranial bleeding ( $p$ $=0.042)$, ischemic stroke $(p=0.042)$, gastrointestinal bleeding $(p=0.0006)$, hip/ pelvic fracture $(p=0.042)$, and asthma $(p=0.0007)$ in WF cohort than RX cohort (Table 2). Also, more numbers of death were reported in WF cohort than RX cohort $(24(6 \%)$ vs. $4(2 \%), p=0.024)$ during 3 -years of the treatment period. No spine or wrist fracture and reduced kidney functions were reported in both cohorts' patients.

\section{Risk factors for the incidence of treatment- emergent event(s)}

Among the enrolled 584 patients of diabetes, 135 had reported one or more adverse events (stroke, bleeding, myocardial infarction, fracture, and/ or asthma) during 3-years of treatment. Among the risk factors, female sex $(p=0.031)$, age $(p=0.035)$ and comorbidities $(p=0.021)$ were associated with incidence of treatmentemergent event(s) (Table 3).

\section{DISCUSSION}

The study reported that diabetic patients with non-valvular atrial fibrillation who received rivaroxaban had the fewer risk of intracranial bleeding, ischemic stroke, and mortality than those who received warfarin during 3-years of treatment. The results of the study were consistent with the results of retrospective analysis [9] and a ROCKET trial on Caucasians patients [12]. With rivaroxaban, a significant risk reduction of thromboembolic events can be found in Chinese diabetic patients with nonvalvular atrial fibrillation.

Fewer numbers of patients suffered from gastrointestinal bleeding in the cohort who received rivaroxaban than those received warfarin. The results of the study were parallel with the results of retrospective analyses [8-10] but were not consistent with a ROCKET trial on Caucasians patients [12]. Rivaroxaban is safe anticoagulant than warfarin.

Fewer numbers of patients suffered from hip/ pelvic fracture and asthma in a cohort who received rivaroxaban than those who received warfarin. The results of the study were parallel with the results of the retrospective analysis [9]. Warfarin inhibits the activation of bone proteins and impairs bone material hardness [13]. Hip/ pelvic fracture during 3-years of treatment is not an acceptable adverse effect hence rivaroxaban can be a good substitute for warfarin.

Trop J Pharm Res, April 2020; 19(4):895 
Table 1: Demographic and clinical characteristics

\begin{tabular}{|c|c|c|c|c|}
\hline \multirow{2}{*}{\multicolumn{2}{|c|}{ Parameter }} & \multicolumn{2}{|c|}{ Cohorts } & \multirow{3}{*}{$\begin{array}{c}\text { Comparison between cohorts } \\
P \text {-value } \\
\end{array}$} \\
\hline & & \multirow{2}{*}{$\begin{array}{l}R X \\
201 \\
\end{array}$} & \multirow{2}{*}{$\begin{array}{l}W F \\
383\end{array}$} & \\
\hline \multirow{4}{*}{ Gender } & & & & \\
\hline & Male & $119(59)$ & $211(55)$ & \multirow{3}{*}{0.38} \\
\hline & Female & $82(21)$ & $172(45)$ & \\
\hline & Minimum & 60 & 60 & \\
\hline \multirow[t]{3}{*}{ Age (years) } & Maximum & 84 & 85 & \multirow[t]{3}{*}{0.07} \\
\hline & Mean \pm SD & $69.52 \pm 4.55$ & $68.69 \pm 5.56$ & \\
\hline & Han Chinese & $179(90)$ & $357(93)$ & \\
\hline \multirow{4}{*}{ Ethnicity } & Tibetan & $3(1)$ & $4(1)$ & \multirow{4}{*}{0.311} \\
\hline & Mongolian & $17(8)$ & $18(5)$ & \\
\hline & North Korean refuge & $2(1)$ & $4(1)$ & \\
\hline & Minimum & 23 & 22 & \\
\hline \multirow[t]{2}{*}{ Body mass index $\left(\mathrm{kg} / \mathrm{m}^{2}\right)$} & Maximum & 29 & 28 & \multirow[t]{2}{*}{0.179} \\
\hline & Mean \pm SD & $25.12 \pm 2.11$ & $24.89 \pm 1.88$ & \\
\hline \multicolumn{2}{|l|}{ Hypertension } & $58(29)$ & 139(36) & 0.08 \\
\hline \multicolumn{2}{|l|}{ Dementia } & $11(5)$ & $25(7)$ & 0.719 \\
\hline \multicolumn{2}{|l|}{ Liver disease } & $4(2)$ & $11(3)$ & 0.6 \\
\hline \multirow[t]{2}{*}{ Depression } & & $17(8)$ & $31(8)$ & \multirow[t]{2}{*}{0.875} \\
\hline & No & $45(22)$ & $88(23)$ & \\
\hline \multirow[t]{3}{*}{ Alcohol abuse } & Previous & $67(33)$ & $129(34)$ & \multirow[t]{3}{*}{0.975} \\
\hline & Current & $89(45)$ & $166(43)$ & \\
\hline & No & $34(17)$ & $61(16)$ & \\
\hline \multirow[t]{2}{*}{ Smoking } & Previous & $81(40)$ & $152(40)$ & \multirow[t]{2}{*}{0.919} \\
\hline & Current & $86(43)$ & $170(44)$ & \\
\hline \multicolumn{2}{|c|}{ Asthma (allergic or trace induced) } & $6(3)$ & $10(3)$ & 0.794 \\
\hline \multicolumn{2}{|c|}{ Diabetes medications } & 131(65) & 225(59) & 0.153 \\
\hline \multicolumn{2}{|l|}{ Hemoglobin $(\mathrm{mg} / \mathrm{dL})$} & $11.45 \pm 1.21$ & $11.78 \pm 2.45$ & 0.07 \\
\hline \multicolumn{2}{|l|}{$\% \mathrm{HbA} 1 \mathrm{C}$} & $7.55 \pm 2.45$ & $7.21 \pm 1.90$ & 0.06 \\
\hline
\end{tabular}

Table 2: Outcome measures during the 3-year treatment

\begin{tabular}{|c|c|c|c|}
\hline \multirow{3}{*}{ Parameter } & \multicolumn{2}{|c|}{ Cohort } & \multirow{2}{*}{$\begin{array}{c}\text { Comparison } \\
\text { between } \\
\text { cohorts }\end{array}$} \\
\hline & $R X$ & $W F$ & \\
\hline & 201 & 383 & $P$-value \\
\hline Intracranial bleeding & 1(1) & $12(3)^{*}$ & 0.042 \\
\hline Ischemic stroke & $1(1)$ & $13(3)^{*}$ & 0.042 \\
\hline $\begin{array}{l}\text { Gastrointestinal } \\
\text { bleeding }\end{array}$ & $2(1)$ & $28(7)^{*}$ & 0.0006 \\
\hline Myocardial infarction & $1(1)$ & $8(2)$ & 0.175 \\
\hline Breast/ prostate cancer & $1(1)$ & $7(2)$ & 0.274 \\
\hline Hip/ pelvic fracture & $1(1)$ & $13(3)^{*}$ & 0.042 \\
\hline Asthma & $4(2)$ & $35(9)^{*}$ & 0.0007 \\
\hline $\begin{array}{l}\text { Variable are shown } \\
\text { Fisher's exact test w } \\
\text { analysis; } p<0.05 \\
\text { *Significantly higher than }\end{array}$ & $\begin{array}{ll}\text { as fre } \\
\text { as per }\end{array}$ & quency & $\begin{array}{l}\text { (percentage). } \\
\text { for statistical } \\
d \text { significant. }\end{array}$ \\
\hline
\end{tabular}

Female sex, age, and the presence of comorbidities were responsible for stroke, bleeding, fracture, and the other treatmentemergent event(s). The results of the study were parallel with the results of the retrospective analysis [9]. Older women have comparatively fewer bone mass density than older men and younger women [14].
Table 3: Multivariate analysis for the incidence of treatment-emergent events $(\mathrm{N}=135)$

\begin{tabular}{|c|c|c|}
\hline Risk factor & $\begin{array}{c}\text { Confidence } \\
\text { interval }\end{array}$ & $P$-value \\
\hline Gender $^{*}$ & $0.55-1.08$ & 0.0 \\
\hline Age (years) ${ }^{*}$ & -1.12 & 0.0 \\
\hline Ethnicity & $5-2.76$ & \\
\hline Body mass index $\left(\mathrm{kg} / \mathrm{m}^{2}\right)$ & 2.12 & 0.062 \\
\hline Comorbidity $^{*}$ & -1.21 & 0.021 \\
\hline Alcohol abuse & $7-2.89$ & 0.089 \\
\hline Smoking & -2.01 & 0.098 \\
\hline Diabetes medications & -2.35 & 0.232 \\
\hline$\% \mathrm{HbA} 1 \mathrm{C}$ & $0.63-1.89$ & 0.095 \\
\hline \multicolumn{3}{|c|}{$\begin{array}{l}\text { Patients who showed no adverse event(s) were } \\
\text { considered as the reference standard. A p-value } \\
0.05 \text { was considered significant. "Significantl) } \\
\text { responsible for adverse event(s) }\end{array}$} \\
\hline
\end{tabular}

Diabetes with the other comorbidities increases the risk of stroke event(s) [3]. Anticoagulants always have the risk of bleeding [10]. The other independent risk factors responsible for stroke, bleeding, fracture, and the other event(s) are required to evaluate for treatment-emergent event(s).

\section{Limitations of the study}

There are several limitations of the analysis, for 
example, the limited sample size has chances of type-I errors in the statistical analysis. The large randomized phase III trial is required to state the hypothesis strongly. The study is not completely generalized because the risk factors for the incidence of embolic events and treatmentemergent adverse effects are different in Caucasians and Chinese patients [1]. The quality of anticoagulation control was not possible because the treatment was for 3-years and the study lacks initial stage pathological results.

\section{CONCLUSION}

Warfarin is an effective treatment for embolic events in elderly Chinese patients with nonvalvular atrial fibrillation but its management is difficult and has high adverse effects. Rivaroxaban appear to show a significant risk reduction of thromboembolic events with manageable treatment-emergent adverse effects.

\section{DECLARATIONS}

\section{Acknowledgement}

Authors are grateful to the medical and nonmedical staff of the Huilongguan Community Health Service Center, Beijing, China.

\section{Conflict of interest}

Authors declared that they have no conflict of interest or any the other competing interest regarding results and/or discussion reported in the research.

\section{Authors' contributions}

The authors declare that this work was done by the authors named in this article and all liabilities pertaining to claims relating to the content of this article will be borne by them. All authors read and approved the manuscript for publication. SW contributed to formal analysis and literature review of the study and draft, review, and edited the manuscript for intellectual content. $R Q$ contributed to the project administration, investigation, data curation, validation, and literature review of the study. $\mathrm{HZ}$ contributed to conceptualization, supervision, resources, data curation, and literature review of the study. The authors agree to be accountable for all aspects of work ensuring integrity and accuracy.

\section{Open Access}

This is an Open Access article that uses a funding model which does not charge readers or their institutions for access and distributed under the terms of the Creative Commons Attribution License (http://creativecommons.org/licenses/by/ 4.0) and the Budapest Open Access Initiative (http://www.budapestopenaccessinitiative.org/rea d), which permit unrestricted use, distribution, and reproduction in any medium, provided the original work is properly credited.

\section{REFERENCES}

1. Huxley RR, Lopez FL, Folsom AR, Agarwal SK, Loehr $L R$, Soliman EZ, Maclehose $R$, Konety $S$, Alonso A. Absolute and attributable risks of atrial fibrillation in relation to optimal and borderline risk factors: The Atherosclerosis Risk in Communities (ARIC) study. Circulation 2011; 123(14): 1501-1518.

2. Huang $B$, Yang $Y$, Zhu J, Liang $Y$, Zhang $H$, Tian $L$, Shao $X$, Wang J. Clinical characteristics and impact of diabetes mellitus on outcomes in patients with nonvalvular atrial fibrillation. Yonsei Med J 2015; 56(1): 62-71.

3. Brambatti $M$, Darius $H$, Oldgren J, Clemens A, Noack HH, Brueckmann M, Yusuf S, Wallentin L, Ezekowitz $M D$, Connolly SJ, et al. Comparison of dabigatran versus warfarin in diabetic patients with atrial fibrillation: Results from the RE-LY trial. Int J Cardiol 2015; 196: 127-131.

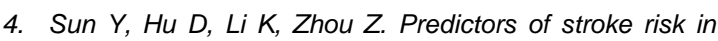
native Chinese with nonrheumatic atrial fibrillation: Retrospective investigation of hospitalized patients. Clin Cardiol 2009; 33(2): 76-81.

5. January CT, Wann LS, Alpert JS, Calkins H, Cigarroa JE, Cleveland JC Jr, Conti JB, Ellinor PT, Ezekowitz MD, Field ME, et al. 2014 AHA/ACC/HRS guideline for the management of patients with atrial fibrillation: a report of the American College of Cardiology/American Heart Association Task Force on Practice Guidelines and the Heart Rhythm Society. J Am Coll Cardiol 2014; 64(21): e1-e76.

6. Xiang $W$, Zhang J., Liu $M$, Liu F, Feng $X$, Wang $Y$. Antithrombotic therapy in elderly patients with nonvalvular atrial fibrillation: A pilot study. Clin Interv Aging 2015; 10: 515-519.

7. De Caterina $R$, Husted $S$, Wallentin L, Andreotti $F$, Arnesen $H$, Bachmann $F$, Baigent $C$, Huber $K$, Jespersen J, Kristensen SD, et al. Vitamin $K$ antagonists in heart disease: Current status and perspectives (Section III). Position paper of the ESC Working Group on Thrombosis--Task Force on Anticoagulants in Heart Disease. Thromb Haemost 2013; 110(6): 1087-1107.

8. Lip GY, Keshishian A, Kamble S, Pan X, Mardekian J, Horblyuk R, Hamilton M. Real-world comparison of major bleeding risk among non-valvular atrial fibrillation

Trop J Pharm Res, April 2020; 19(4):897 
patients initiated on apixaban, dabigatran, rivaroxaban, or warfarin. A propensity score matched analysis. Thromb Haemost 2016; 116(5): 975-986.

9. Norby $F L$, Bengtson $L G$, Lutsey $P L$, Chen $L Y$, MacLehose RF, Chamberlain AM, Rapson I, Alonso A. Comparative effectiveness of rivaroxaban versus warfarin or dabigatran for the treatment of patients with non-valvular atrial fibrillation. BMC Cardiovasc Disord 2017; 17(1). DOI: 10.1186/s12872-017-0672-5.

10. Cunningham A, Stein $C M$, Chung $C P$, Daugherty JR, Smalley WE, Ray WA. An automated database case definition for serious bleeding related to oral anticoagulant use. Pharmacoepidemiol Drug Saf 2011; 20(6): 560-566.

11. Salem AM, Bamosa AO, Qutub HO, Gupta RK, Badar A, Elnour A, Afzal MN. Effect of Nigella sativa supplementation on lung function and inflammatory mediators in partly controlled asthma: A randomized controlled trial. Ann Saudi Med 2017; 37(1): 64-71.

12. Patel MR, Mahaffey KW, Garg J, Pan G, Singer DE, Hacke W, Breithardt G, Halperin JL, Hankey GJ, Piccini $J P$, et al. Rivaroxaban versus warfarin in nonvalvular atrial fibrillation. N Engl J Med 2011; 365(10): 883-891.

13. Sugiyama $T$, Kugimiya $F$, Kono $S$, Kim $Y T$, Oda $H$. Warfarin use and fracture risk: An evidence-based mechanistic insight. Osteoporos Int 2015; 26(3): 12311232.

14. Sugiyama T, Takaki T, Sakanaka $K$, Sadamaru H, Mori $K$, Kato $Y$, Taguchi $T$, Saito $T$. Warfarin-induced impairment of cortical bone material quality and compensatory adaptation of cortical bone structure to mechanical stimuli. J Endocrinol 2007; 194(1): 213-222. 